\title{
Relações de poder e
}

\section{representações sociais do \\ machismo na obra Dôra, Doralina de Rachel de Queiroz}

Marcos Vinicius Ferreira Trindade

\section{Resumo}

Neste artigo analisam-se os efeitos da dominação masculina dos personagens Laurindo e Comandante sobre a protagonista Dôra no discurso literário de Rachel de Queiroz, notável escritora do Modernismo no Brasil que retrata as representações sociais tanto do feminino quanto do masculino, evidenciando principalmente as relações de poder entre os gêneros. Nesse sentido, busca-se compreender os efeitos históricos do poder da dominação masculina por meio do pensamento de Bourdieu na relação entre os personagens ao longo do enredo.

Palavras-chave: Gênero - Poder - Discurso Literário. 


\section{Introdução}

A literatura como fonte de representação social histórica que reproduz as diferentes experiências humanas na sociedade em seus aspectos físicos e psicológicos, ajuda a história social a entender os sujeitos e as suas ações em determinada época. Portanto, a literatura consiste num documento histórico potencial para a investigação das representações sociais tradicionais de gênero para historiadores/historiadoras recuperarem as visões históricas por meio do modo como escritores/escritoras constituíram as relações de gênero no texto literário.

No Brasil, nas primeiras décadas do século XX ocorreram mudanças sociais significativas, principalmente nas relações de gênero. Se homens e mulheres são sujeitos sociais historicamente situados, então qualquer análise das relações estabelecidas entre homens e mulheres não pode perder de vista a noção de gênero. Por meio dessa categoria podemos compreender o modo como ocorre, por exemplo, a divisão dos papéis sociais nas relações entre os gêneros.

Dessa forma, este trabalho está estruturado nas seguintes seções: a primeira busca discutir o modo como o homem é representado como dominador, apoiando-se na teoria da dominação masculina, proposta por Pierre Bourdieu, que discute a invisibilidade do poder nos modos de (re)produção das diferenças entre gêneros. Na seção seguinte, apresentamos brevemente a trajetória da escritora Rachel de Queiroz, bem como os personagens e o enredo da obra Dôra, Doralina. Por fim, nas seções seguintes seguimos com a análise das representações sociais históricas da dominação masculina com foco sobre os papéis sociais de Laurindo e Comandante em relação à protagonista, em duas seções distintas, na tentativa de compreender de que modo se dá a presença dessa dominação na vida da protagonista e como sua vida passa a girar em torno da figura masculina.

\section{O homem como figura dominadora no mercado de bens simbólicos}

Com base no pensamento de Bourdieu, os comportamentos e o modo de comunicação que se estabelecem entre homens e mulheres são marcados pelo poder, e o discurso literário consiste numa fonte histórica potencial para observamos a constituição das representações sociais de gênero. A representação social consiste em "uma modalidade de conhecimento particular que tem por função a elaboração de comportamentos e a comunicação entre indivíduos" 
(MOSCOVICI, I978, p. 26). Portanto, compreende-se que as disparidades vivenciadas pelas mulheres em relação aos homens se deve ao modo de compreensão estabelecido por uma ordem social masculina cuja força "se evidencia no fato de que ela dispensa justificação: a visão androcêntrica impõe-se como neutra e não tem necessidade de se anunciar em discursos que visem a legitimá-la" (BOURDIEU, 2007, p. I8). Dessa forma, pode-se observar os efeitos históricos da dominação masculina tanto em estado objetivado quanto subjetivado, em modos privados e públicos, conferindo poderes materiais e simbólicos aos homens. As relações de poder entre os gêneros são construções sociais que variam dentro da própria sociedade. Nogueira aponta que

[...] a ideologia dominante, por meio de seu discurso construído, partilhado e difundido tanto em nível disciplinar como político, consegue manter uma ordem social que perpetua as desigualdades e o sexismo. Assim, é importante considerar a linguagem desse discurso como elemento fundamental da construção da subjetividade masculina e da feminina, e da manutenção das relações sociais e de poder, para que se possa teorizar a respeito da construção social do gênero (NOGUEIRA apud PRAUN, 2OII, p. 62).

De modo semelhante a Nogueira, que evidencia também o aspecto da ideologia, para Saffioti o patriarcado é um sistema de relações sociais que garante a subordinação da mulher ao homem, e que "não se resume a um sistema de dominação, modelado pela ideologia machista. Mais do que isto, ele é também um sistema de exploração" (SAFFIOTI, I987, p. 50). Contudo, essa autora considera a dominação masculina ou machismo não somente um sistema de dominação, mas também um sistema de exploração.

Uma das formas de dominação masculina em estado objetivo e também de discriminação é a especificidade de trabalhos com base na distinção dos sexos, conforme argumenta Bourdieu quando diz que

[...] a diferença biológica entre os sexos, isto é, entre o corpo masculino e o corpo feminino, e, especificamente, a diferença anatômica entre os órgãos sexuais, pode assim ser vista como justificativa natural da diferença socialmente construída entre os gêneros e, principalmente, da divisão do trabalho (BOURDIEU, 2007, p. 20).

Logo, a divisão social do trabalho consiste em um dos diversos aspectos marcados pelo poder simbólico da ordem social masculina. Sobre o poder, Foucault argumenta que: 
[...] não é algo que se adquire, arrebate ou compartilhe, algo que se guarde ou deixe escapar; o poder se exerce a partir de inúmeros pontos e em meio a relações desiguais e móveis; que as relações de poder não se encontram em posição de exterioridade com respeito a outros tipos de relações (processos econômicos, relações de conhecimentos, relações sexuais), mas lhe são imanentes; são os efeitos imediatos das partilhas, desigualdades e desequilíbrios que se produzem nas mesmas e, reciprocamente, são as condições internas destas diferenciações (I999, p. 89).

Dessa forma, as relações de gênero são mantidas de formas desiguais, pois homens e mulheres são concebidos de forma hierárquica. Scott define gênero como sendo "um elemento constitutivo das relações sociais baseadas nas diferenças percebidas entre os sexos [...] uma forma primária de dar significado às relações de poder" (SCOTT, I990, p. 86). Logo, compreendemos que a construção das representações dos papéis sociais para homens e mulheres tem por base a distinção entre os sexos, que resulta em relações de poder.

Em suma, Bourdieu compreende que a violência simbólica se reafirma na medida em que são reproduzidos conceitos equivocados de superioridade masculina nos mais diversos âmbitos da sociedade, de modo que em determinados momentos os sujeitos tanto masculino quanto feminino nem percebem que estão reproduzindo esse modelo de dominação, devido à naturalização dos costumes, ou, como denomina Bourdieu, habitus ${ }^{\mathrm{I}}$. Com base na teoria da dominação masculina, o homem é o sujeito e a mulher o objeto no mercado de bens simbólicos. Assim, o homem é quem detém o poder na sociedade e a mulher é reduzida a mero objeto, pois fica subordinada à figura masculina.

\section{Algumas considerações sobre a autora Rachel de Queiroz e a sua obra Dôra, Doralina}

Diversas obras trazem à tona representações sociais assimétricas de gênero. Optou-se por trabalhar com o romance Dôra, Doralina de Rachel de Queiroz, pois a temática deste trabalho é bastante evidente na obra.

A escritora, nascida em I7 de novembro de I9IO na cidade de Fortaleza, parente pelo lado materno do escritor cearense José de Alencar, é considerada

I Conceito fundamental de Bourdieu, habitus é um sistema de arranjos que denomina o modo de ser. São estruturas já feitas que provocam outras estruturas, formando assim a prática e as representações do sujeito. 
por muitos como a mais expoente escritora do regionalismo do Romance de I930, tendo começado sua carreira nas letras e no jornalismo ${ }^{2}$ ainda na juventude. Aos 20 anos publica $O$ Quinze, obra que lhe abre as portas do cenário literário do país. Em I977, torna-se a primeira mulher a entrar para a Academia Brasileira de Letras, destacando-se por abordar em suas obras algumas questões sociais pertinentes ao momento [ABL, 20--?].

O romance Dôra, Doralina é constituído por três livros: o primeiro intitulado Livro de Senhora, descreve a vida de Dôra na fazenda Soledade, sua infância, juventude e os eventos de sua vida adulta, como o seu casamento com Laurindo e a sua viuvez; o segundo livro, Livro da Companhia, relata como Dôra, depois da viuvez, transforma-se em uma mulher livre de seus primeiros dominadores, Senhora e Laurindo, tornando-se atriz da Companhia de Comédia e Burletas Brandini Filho, momento no qual sua identidade em relação aos seus dominadores é ressignificada; por fim, o último livro denomina-se Livro do Comandante, no qual é descrito o primeiro amor verdadeiro de Dôra, que faz que ela mais uma vez seja dominada até a morte do segundo marido. Com a morte do Comandante, Dôra retorna para a fazenda Soledade como única dona de tudo que um dia foi de Senhora.

\section{Laurindo: o primeiro marido e a dor}

No Livro de Senhora é apresentado ao leitor o personagem Laurindo, primo dos integrantes da família que se torna agrimensor da fazenda Soledade depois de resolver alguns problemas com as divisas da propriedade. Embora o interesse de Laurindo por Senhora seja nítido já nas primeiras impressões, é importante lembrar de que a dona da fazenda Soledade não desejava ter outro marido "depois de conhecer a sua força de viúva" (QUEIROZ, 2004, p. 4I), o que faz que Laurindo então comece a inclinar-se para o lado de Dôra.

Laurindo tinha 45 anos e Dôra, 22. É a partir dessa diferença de idade que se iniciam os rumores nas redondezas de que o personagem estava afeiçoado na verdade por Senhora que ainda conservava beleza e atributos. Sur-

2 A profissão de jornalista surge no século XV, relacionada à invenção da prensa de Gutemberg, que revolucionou a história da leitura e a circulação de ideias, agora impressas. Derivando do francês, jour ("dia") e analyste ("analista"), percebe-se a gênese da profissão: analisar o cotidiano. Rachel nunca chegou de fato a graduar-se em jornalismo, porém utilizava com orgulho esse título devido ao seu local de trabalho. Na realidade, pode-se dizer que ela era mais cronista, tradutora e escritora do que propriamente jornalista. 
gem então os boatos de que Laurindo casou-se com Dôra por questões financeiras uma vez que seria ela a única herdeira da Soledade e, sendo assim, ele também herdaria tudo, visto que o que pertencia à mulher também era do marido. Pode-se entender o relato no trecho do romance que segue:

- Mas qual foi a história, Xavinha? Era comigo?

Aos poucos, com muitas mordidas de beiço e palavras sussurradas, o caso foi saindo. Não vê, ela encontrou D. Dagmar na farmácia - encontrou, não, a mulher tinha que estar lá, já que a farmácia é dela, o marido vive na rua, não quer saber de balcão:

- Quando eu pedi um vidro de Elixir Paregórico ela perguntou logo se era para a noivinha - se a noivinha já estava com os seus antojos...

Já daí Xavinha não gostou, andarem especulando as coisas da fazenda, de gente especula ela tem ódio; e assim foi respondendo séria que na Soledade por enquanto ainda não se fala em menino novo. E então D. Dagmar disse que na rua foi a maior admiração com o resultado do casamento, tinha gente nas Aroeiras que até fez aposta como casava a velha e não a moça. Seu Carmélio de Paula foi um. Mas o tabelião, aquele Esmerino, tinha dito ali mesmo no balcão da farmácia que cobria qualquer aposta: Laurindo casava era com a moça:

- Não vê que casando com a viúva ele só pega metade da meação dela, porque a outra metade é a herança da filha? Mas casando com a moça leva logo a legítima do pai e depois vem a herança da mãe, direta, sem repartimento...

E seu Carmélio disse que podia ser, de herança ele não entendia, mas entendia de gente, e duvidava muito que de qualquer jeito o agrimensor botasse a mão num vintém de nada, a não ser por morte da velha... (QUEIROZ, 2004, p. 43-44).

Segundo Dôra, o seu marido "vivia quase sempre fora de casa, a serviço" (QUEIROZ, 2004, p. 226). De acordo com a teoria da dominação masculina proposta por Bourdieu, o homem deveria ser o provedor, abastar a casa com alimentos e dinheiro, não deixando faltar nada a sua esposa, mantendo dessa forma a mulher dependente financeiramente. Contudo, isso era algo que Laurindo não fazia, pois "a vida de agrimensor é incerta, só se ganha quando chamado" (QUEIROZ, 2004, p. 85), além de não dar dinheiro à Dôra, muito menos ajudava nas despesas da casa. Portanto, as representações sociais de gênero identificadas na relação entre Dôra e o seu primeiro marido, bem como com a Senhora, são marcadas pelo poder - mas ao contrário do que argumenta Bourdieu, pois é a dona da Soledade quem assegura o sustento tanto da filha quanto de Laurindo. 
Por um lado, para a dominação masculina, identidade do homem perante outros homens e perante a sociedade, a vida incerta de Laurindo era algo problemático; por outro, seguia a lógica do costume da época em que o romance é ambientado, na qual o homem não deveria se preocupar com o cotidiano da casa, pois era a esposa que deveria manter o lar agradável ao marido. Conforme Maluf e Mott, o marido não precisava ser "incomodado com pedidos de ajuda. O dever da esposa era, ao contrário, aliviá-lo de qualquer contrariedade e esforço: pois não trabalhou ele o dia inteiro para ganhar o pão cotidiano da família?” (MALUF; MOTT, I998, p. 420). Laurindo perante Senhora era uma figura subalterna: também reprimido por Senhora, só trabalhava quando havia serviço. Logo, não tendo tantos provimentos para bancar os custos da fazenda ele era apenas mais um na rede de dominação da dona da Soledade.

A hierarquia entre os gêneros garantia a ordem familiar. A mulher e os filhos deveriam ser protegidos e sustentados pelo marido/pai, pois este deveria ser o provedor do lar. As atividades laborais conferiam ao marido poder, e aqueles homens que, por determinado motivo, estivessem impossibilitados de manterem sozinhos o sustento da família de forma satisfatória, "cometiam suicídio, justificando o ato pela derrota moral de não cumprir o seu dever" (MALUF; MOTT, I998, p. 38I). Os papéis estavam bem definidos, e era tido como desonra um homem não custear os provimentos de sua família.

Mesmo Dôra nunca sonhando com casamento, casou-se sem amor para manter os interesses da família. Maluf e Mott apontam que

[...] as conveniências econômicas e os interesses de classe moveram a linha de parentela para relacionamentos mais horizontais, uma vez que a riqueza tornou-se um critério de status muito mais importante. Os vínculos matrimoniais eram garantia de controle sobre o poder, da mesma forma que funcionavam como proteção contra as frequentes ameaças de desastres econômicos (MALUF; MOTT, I998, p. 390-39I).

Assim, tendo Laurindo uma profissão e sendo parente, torna-se um bom partido para a herdeira da Soledade, que já estava passando da época de casar. O casamento entre os dois foi mais uma convenção para a sociedade vigente, pois não havia amor entre eles - algo que a própria protagonista admitia, ao afirmar que não era "uma vida igual à dos outros casais na sua casa. Começava por aquela não ser a nossa casa, e se poderia dizer que nós éramos mais como um casal de meninos, brincando emprestado de marido e mulher" (QUEIROZ, 2004 , p. 85). Laurindo, como o único homem da Soledade, tinha direito a 
tudo, inclusive respeito. Mas o casamento durou apenas três anos, dois meses e dezessete dias.

Ao descobrir a traição de Laurindo com Senhora, Dôra fica desolada, pois acreditava que o marido era a única coisa que tinha, ao contrário de sua mãe, que tinha poder, visto que se sentia como uma estrangeira em sua própria casa. A protagonista, revestida de dor - e até mesmo com consciência de suas palavras -, sugere que seria melhor a morte para viver sem a dor. Depois de dizer a Delmiro, o jagunço que vivia sob sua proteção, que o "jeito, só a morte" (QUEIROZ, 2004, p. 93), Laurindo sofre um acidente com a espingarda, levando Dôra à sua tão sonhada liberdade. Embora no romance o que acontece ao marido de Dôra seja colocado como um acidente, é importante ressaltar a promessa feita por Delmiro ao chegar à Soledade: pegaria novamente em uma arma por ordem de Dôra, e apenas para protegê-la. Ao dizer que o “jeito, só a morte”, Delmiro entende a frase como uma ordem da protagonista, e fica implícito que foi ele o assassino de Laurindo. Dessa forma, as representações sociais do feminino em relação à ordem social masculina, conforme diz Bourdieu, são desestabilizadas, pois mesmo a protagonista fragilizada pela dor da traição tanto de seu marido quanto de sua mãe mobiliza as "armas simbólicas" que estão ao seu alcance. A morte representa não somente o final, mas um novo recomeço, uma outra trajetória social para Dôra - semelhante ao que acontece numa outra obra da mesma autora, Memorial de Maria Moura, cuja personagem também mobiliza o que está ao seu alcance em favor de sua liberdade em relação ao poder exercido pela figura masculina.

O luto de Dôra é marcado mais pela dor da traição do que pela perda do marido: usou cores de viúva somente no velório, escolhendo depois vestir-se de azul, demonstrando que ele não tinha mais importância. Era hora de nascer uma nova mulher, forte e de resistência. Sobre o luto, Dôra diz que "era o meu documento de viuvez [...] O luto, ali, ainda era o passaporte da viúva; me garantia o direito de viver sozinha sem ninguém me perturbar em nada, de mandar e desmandar [...]" (QUEIROZ, 2004, p. 409).

\section{v. Comandante: o amor verdadeiro e mais uma dor}

Asmodeu é a última figura que representa a dominação sobre Dôra. O primeiro encontro acontece no navio no qual ele era Comandante, que transportava as pessoas de uma margem à outra da costa brasileira. Informamos que Rachel de Queiroz coloca em questão a dificuldade de locomoção aérea 
durante a Segunda Guerra Mundial, motivo pelo qual a Companhia de Teatro passou a viajar de navios.

O significado do nome de batismo do Comandante manifesta o seu temperamento, pois quando indagado se o seu nome era Amadeu, sentia-se desconfortável, fazendo perceber que não gostava dessa confusão. E sobre o significado de um nome tão singular, explica:

- Justamente, é um demônio. E recitou:

- Asmodeu, entidade diabólica que figura no livro de Tobias como sendo o demônio dos prazeres impuros... Também tem sido chamado "o diabo coxo". Levanta os telhados das casas e descobre os segredos dos seus habitantes (QUEIROZ, 2004, p. 23I).

Comandante também adota o nome de "cadete Lucas" no Rio de Janeiro, por ser contrabandista e precisar de um nome diferente para fazer negócios. Percebe-se que são três nomes distintos, cada um sendo utilizado conforme a ocasião. Assim, o interessante é compreender que o nome de batismo remetia a um diabo, pois revelava uma de suas características: o gênio forte. Era chamado de Comandante porque além de ser de fato comandante de um navio, esse nome é uma clara metáfora do que ele representará na vida de Dôra: ele a comandará do início do relacionamento até a sua morte, e a vida da protagonista girará em torno dele. Nessa altura do romance, observa-se a reiteração de representações sociais nos termos da ordem social masculina, pois as representações sociais do feminino de Dôra confirmam a sua submissão em relação ao seu segundo companheiro. No mercado de bens simbólicos, força, virilidade e agressividade são adjetivos que caracterizam as representações sociais do masculino, ao contrário dos predicativos de fragilidade e doçura, que reiteram representações sociais do feminino marcadamente falocráticas.

Dôra não era mais uma garota ingênua, chegando a ponto de receber homens em seu camarim, mas sempre se desviando dos assédios. Fazia isso pois sabia que o Comandante sentia ciúmes, e ela gostava desse sentimento por parte do homem que amava. Percebe-se que diferente de Laurindo, Asmodeu custeava as necessidades de Dôra, mesmo ainda não estando casados, quando em apenas para um convite para jantar lhe diz: "você é a minha mulher, eu tenho o direito de lhe sustentar" (QUEIROZ, 2004, p. 257).

A Dôra independente, livre e atriz de teatro cede lugar novamente à Dôra submissa, dessa vez não à figura materna, mas sim à de um homem. O Comandante ama Dôra, mas não existe uma cumplicidade entre o casal, uma vez que ela abandona tudo - a companhia e a sua liberdade - para viver esse amor, 
enquanto ele continua com a sua vida, tornando-se o dominador da protagonista. E ao que parece, Dôra sentia-se confortável com essa nova situação que começava a vivenciar, dispondo-se até em realizar atividades que confirmavam sua condição de submissa:

Meu Deus, e se eu pudesse, eu é que dava dinheiro a ele, cozinhava, lavava e passava pra ele, lhe engraxava os sapatos, fazia as coisas mais humildes que eu nunca tinha feito na vida, nem pra mim mesma! E me ri - se Xavinha escutasse - eu, que na Soledade tinha uma cunhã até para me lavar o cabelo! (QUEIROZ, 2004, p. 257-258).

Asmodeu revela-se um marido ciumento e possessivo. O Código Givil Brasileiro de $1916^{3}$ assegurava a inferioridade da mulher casada ao marido e buscava mostrar como cada cônjuge deveria portar-se para garantir a ordem do núcleo familiar. O código colocava a esposa como dependente do homem, o que mostrava certa desumanização da mulher, sobre quem os "poderes masculinos" caíam, uma vez que o uso da violência "legítima" era permitida. Segundo Maluf e Mott (I998), ao ser desobedecido, o homem se sentia na obrigação de castigar a sua mulher como uma espécie de "costume" daquele período. A violência doméstica é retratada em determinados momentos do Livro do Comandante. Em um desses jogos de ciúmes, Dôra dança com outro homem, atitude desaprovada por Asmodeu, que chega a agredir sua companheira:

Quando chegamos em casa, quase de manhã, e eu já tirava a minha roupa, ele parece que de repente se lembrou da cena. Porque me arrancou o vestido da cabeça e me deu um tapa tão forte na face que deixou marca dos seus quatro dedos: - Isso é pra você se lembrar de nunca mais na vida sair dançando com outro homem. A sorte de vocês foi eu estar desarmado - não deixarem entrar revólver naquela espelunca! (QUEIROZ, 2004, p. 30I-302).

"Justifica-se" a agressão pelo fato de Asmodeu ser o homem e o novo provedor de Dôra, e cabendo à mulher a responsabilidade de manter a compostura desejada pela sociedade da época. Conforme aponta Rachel Soihet (I997), era dada razão à medicina social, que atribuía característica como sagacidade, sexualidade aflorada e robustez aos homens, diferente dos adjetivos reservados

3 O Código Givil instituído no Brasil em I9I6 determinava a capacidade civil, os direitos pertencentes à família e as relações pessoais entre marido e mulher, além de regimentar os bens no casamento. 
às mulheres, como mencionado. Lombroso ${ }^{4}$ era defensor dessa teoria, que servia para explicar tantos os crimes passionais quanto a violência que as mulheres sofriam. Assim, o uso da força, em muitos casos, era mobilizado para a não realização de desejos próprios, uma forma rígida de manter o controle sobre a mulher. Saffioti define esse ato de força como "a ruptura de qualquer forma de integridade da vítima, seja de forma física, psíquica, sexual ou moral" (SAFFIOTI, 2004, p. I7).

O Comandante era contrabandista, chegando a ficar preso durante um tempo. Dôra estava tão mergulhada na submissão que mesmo preocupada com o fato não demonstrava que se importava quando o seu companheiro saísse da prisão, pois poderia incomodá-lo, e não queria isso. O Comandante passa a ser sua direção: foi ele quem deu "comando" quando ela ainda sentia-se amargurada pelo que acontecera na fazenda Soledade - uma clara metáfora que uma mulher somente poderia seguir com a vida se estivesse ao lado de um homem, não importando a sua atividade.

A relação de dominação também se dispõe por atos sexuais, nos quais as mulheres não deveriam ter liberdades e ensejos. Além disso, as relações sexuais entre marido e esposa deveriam ser decentes - segundo a visão sociocultural construída, principalmente por ideologias religiosas, na qual apresenta sua base em padrões tidos como éticos e morais - e dentro do lar. É imposta também a virilidade masculina, a qual segundo Bourdieu "é uma noção eminentemente relacional, construída diante dos outros homens, para os outros homens e contra a feminilidade, por uma espécie de medo do feminino, e construída, primeiramente, dentro de si mesmo" (BOURDIEU, 2007, p. 67). Percebe-se então que o homem também é submisso, porém a si mesmo. Há sempre que mostrar-se viril e precisa ter atitudes distintas das mulheres para reafirmar sua sexualidade e honra até mesmo para outros homens.

Dessa forma, a identidade do homem em relação à identidade da mulher será distinguida pela força e virilidade, e serão esses atributos que irão estabelecer uma hierarquia entre os gêneros. Com o patriarcado, o homem passa a ser o referencial da sexualidade e da robustez, cabendo às mulheres apaziguar a "sensualidade do casal" (MALUF; MOTT, I998, p. 392), pois ela deveria colocar o respeito à frente do prazer. A noite de núpcias, por exemplo, vai

4 Lombroso baseava sua antropologia criminal na interpretação de pesquisas empíricas das características físicas, fisiológicas e psicológicas do indivíduo criminoso. No que se refere às violências sofridas pelas mulheres, afirmava que o sexo feminino seria responsável pelas violências sofridas devido a seu gênero. 
ser um episódio que marcará essa dualidade, tendo de um lado a ingenuidade da mulher virgem, que cria até mesmo fobia daquele momento e, do outro, o homem com sua virilidade que poderia cometer até mesmo uma "violação legal" da sua companheira, segundo Maluf e Mott (I998).

Com a morte do Comandante, que contraiu tifo e não sobreviveu, Dôra mais uma vez tem a dor ao seu lado. A dominação masculina é rompida novamente, dessa vez sem a sombra da dominação imposta por Senhora, e a protagonista torna-se independente novamente. Retornando ao seu lugar de origem, Dôra só consegue sentir-se sozinha, e

[...] passados os dias piores do choque, eu olhava tudo em meu redor como casas e gente de uma cidade estrangeira, e ouvia a língua do povo como uma língua estrangeira, e o meu instinto só me pedia para ir embora, voltar para longe, onde a dor que me podia doer era uma dor que eu conhecia, não aquela dor que para mim só tinha sido dele, só dele e nada mais.

Nenhuma hora do Rio tinha eu vivido sem ele [...] (QUEIROZ, 2004, p. 406).

Compreende-se que Dôra demonstra despreparo em ser um sujeito independente novamente, livre das amarras da dominação do seu falecido marido. O poder exercido pelo Comandante foi forte - o que, conforme Bourdieu, consiste num "poder invisível, o qual só pode ser exercido com a cumplicidade daqueles que não querem saber que lhe estão sujeitos ou mesmo que o exercem” (BOURDIEU, 200I, p. 7-8). A morte do dominador também é a morte da felicidade futura de Dôra. Portanto, as representações sociais do feminino de Dôra e de Senhora não são as mesmas, pois a diferença entre uma e outra está no fator econômico: enquanto a representação social do feminino de Senhora é a de uma mulher independente, forte e dominadora, inclusive da figura masculina - no caso, do personagem masculino Laurindo -, a representação social do feminino de Dôra ora reitera a ordem social masculina, ora desestabiliza a força da estrutura da dominação masculina.

\section{Iv. Considerações finais}

Por meio de obras de escritores como Rachel de Queiroz, que contribuiu com seus romances para fomentar debates acerca das conjunturas sociais vigentes, pode-se ver um Brasil com diversas faces, com sua diversidade regional e cultural, mas também com dificuldades explícitas, como a miséria, as opressões e a dominação masculina sobre as mulheres. 
O discurso da escritora tornou-se um valioso objeto de análise para entender as representações sociais históricas do machismo. Assim, ao longo deste estudo percebeu-se que as representações sociais de gênero marcadas pela invisibilidade do poder simbólico da ordem social masculina ora eram desestabilizadas, ora eram reafirmadas.

Já no nascimento, com base nas diferenças biológicas entre homens e mulheres, cada corpo é representado com uma carga cultural específica. Passase a ser homem ou mulher, uma construção social que ao longo da história esteve marcada por diferenças e hierarquias. Apesar das representações sociais de gênero dos dois principais personagens masculinos, Laurindo e Comandante, serem marcadamente dominantes, Dôra, Doralina, cansada de ser oprimida pelos efeitos da estrutura social da dominação masculina, busca a transformação da sua condição de submissa.

\section{Referências}

ACADEMIA BRASILEIRA DE LETRAS. Bibliografia de Rachel de Queiroz. 20--?. Disponível em <https://bit.ly/2vRSpJX>. Acesso em: 25 out. 2016.

BOURDIEU, P. O poder simbólico. In: . Sobre o poder simbólico. Tradução de Fernando Tomaz. 4. ed. Rio de Janeiro: Bertrand Brasil, 200I. p. 7-I6.

. A dominação masculina. Tradução de Maria Helena Kühner. 5. ed. Rio de Janeiro: Bertrand Brasil, 2007.

FOUCAULT, M. História da sexualidade: a vontade de saber. Tradução de Maria Thereza da Costa Albuquerque e J.A. Guilhon Albuquerque. I3. ed. Rio de Janeiro: Graal, I999. v. I.

MALUF, M.; MOTT, M. L. Recônditos do mundo feminino. In: NOVAIS, F.; SEVGENKO, N. (Orgs.). História da vida privada no Brasil: República: da belle époque à era do rádio. São Paulo: Companhia das Letras, I998. p. 368-422.

MOSGOVICI, S. A representação social da psicanálise. Tradução de Álvaro Gabral. Rio de Janeiro: Zahar, 1978.

NOGUEIRA, C. Um novo olhar sobre as relações sociais de género: feminismo e perspectivas críticas na psicologia social. Lisboa: Fundação Galouste Gulbenkian, 200I.

PRAUN, A. G. Sexualidade, gênero e suas Relações de poder. Húmus, São Luís, v. I, $\mathrm{n}^{\mathrm{O}} \mathrm{I}, \mathrm{p} .55^{-65}$, $201 \mathrm{I}$.

QUEIROZ, R. Dôra, Doralina. 20. ed. Rio de Janeiro: José Olympio, 2004.

SAFFIOTI, H. O poder do macho. São Paulo: Moderna, I987. Gênero, patriarcado, violência. São Paulo: Fundação Perseu Abramo, 2004. 
Relações de poder e representações sociais do machismo...

SCOTT, J. Gênero: uma categoria útil de análise histórica. Educação e Realidade, Porto Alegre, v. 20, n. 2, p. 7I-99, I990.

SOIHET, R. Mulheres pobres e violência no Brasil urbano. In: DEL PRIORE, M. (Org.); BASSANEZI, Carla (Coord.). História das mulheres no Brasil. 2. ed. São Paulo: Contexto: Unesp, I997.p. 362-40o.

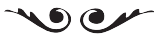

Marcos Vinicius Ferreira Trindade é licenciado em História pela Universidade Federal do Maranhão. marcostrindade93@gmail.com 